\title{
IODATE OXIDATION OF N-ACETYL L-CYSTEINE: APPLICATION IN DRUG DETERMINATION AND CHAR- ACTERIZATION OF ITS OXIDATION AND DEGRADATION PRODUCT BY MASS SPECTROMETRY
}

\author{
MASOOM RAZA SIDDIQUI ${ }^{1}$, SAIKH MOHAMMAD WABAIDUR ${ }^{1}$, ZIED A. ALOTHMAN", HABIBUR RAHMAN", \\ MD. SARFARAZ ALAM ${ }^{3}, M D$. SAJID ALI ${ }^{3}$
}

\author{
${ }^{I}$ Chemistry department, College of Science, King Saud University, Riyadh, Saudi Arabia \\ ${ }^{2}$ Chemistry Department, Aligarh Muslim University, Aligarh, U.P. India. \\ ${ }^{3}$ College of Pharmacy, Jazan University, Jazan, Saudi Arabia. \\ (Received: April 26, 2013 - Accepted: December 24, 2013)
}

\begin{abstract}
A kinetic spectrophotometric method based on the initial rate measurement has been developed for the determination of N-acetyl L-cysteine. The developed method is based on the oxidation of $\mathrm{N}$-acetyl L-cysteine with iodate. The reaction product was studied and characterized using the mass spectrometry and the structure of the product was proposed. From the mass spectrometric studies it was concluded that the oxidation of the drug resulted in the formation of a disulfide. The developed method was validated as per the guidelines of international conference on harmonization. The developed initial rate method was found to be linear in the concentration range of $1.25-30 \mu \mathrm{g} \mathrm{ml}^{-1}$. The detection and quantitation limits were found to be 0.018 and $0.056 \mu \mathrm{g} \mathrm{ml}{ }^{-1}$. In the current study, the degradation product of $\mathrm{N}$-acetyl L cysteine was also prepared and identified using mass spectrometry.
\end{abstract}

Keywords: N- acetyl cysteine, Initial rate method, Spectrophotometry, mass spectrometry

\section{INTRODUCTION}

$\mathrm{N}$-acetyl-L-cysteine (NAC) is commonly known as N-acetyl cysteine or acetyl cysteine. It is a pharmaceutical compound, which is also used as a nutritional supplement. It is derived from an amino acid L-cysteine. Acetyl cysteine has been used against the acetaminophen - induced toxicity. Oral route of administration is preferred unless contraindications such as aspiration or excessive vomiting exist ${ }^{1}$. However, intra venous formulation has also been approved by Food and Drug Administration (FDA) which has its own advantage of reducing the dosing schedule from 72 hours to 20 hours ${ }^{2}$. Another important use of NAC is in restoring of the glutathione stimulating hormone level ${ }^{3}$. It is also used in the treatment of respiratory disorders by acting as a mucolytic agent. NAC acts by breaking of disulfide bonds in proteins. It can also be used as metal chelating agent for various toxic metals such as cobalt, boron, cadmium lead and arsenic ${ }^{4,5}$. Owing to its pharmacological importance, analytical methods have been reported in the past few years for the quantitation of $\mathrm{N}$-acetyl L-cysteine in various matrix. The developed methods include fluorimetry ${ }^{6}$, high performance liquid chromatography (HPLC) ${ }^{7,8}$, potentiometry ${ }^{9}$ and spectrophotometry ${ }^{10,11}$. In the literature, a kinetic based method is available that include the application of buffers ${ }^{12}$ which makes the quantitation process a bit lengthy, in the methods involving buffers numerous $\mathrm{pH}$ points are selected $(2.0-8.0)$ to prepare the Britton-Robinson buffer, further the trial and selection of the proper buffers solution is itself an addition and tedious process. The method involves other two reagents in addition to the buffer which means lot of trails and investigations are performed to optimize the proper reaction condition as in the article authors investigated molar ratio of $\mathrm{Cu}^{\mathrm{II}}$ and neocuproine in the reaction mixture. Therefore, a more simple kinetic method is offer to estimate $\mathrm{N}$-acetyl $\mathrm{L}$ cysteine in its dosage forms which neither require costly reagents nor the expensive instrumentation except the characterization part. Further in the reaction, only two reagents in aqueous medium are involved where only concentrations need to be optimized.

\section{EXPERIMENTAL}

\section{Apparatus}

All Absorbance measurements were performed on Evolution 300, Thermo manufactured, UV-visible spectrophotometer with matched quartz cell. Waters Aquity UPLC-MS system was employed to characterize the oxidation and degradation product.

\section{Reagents and standards}

All the reagents and chemicals used in the current analytical development process were of analytical grade. N-acetyl L cysteine was purchased from Merck, Darmstadt. Reference standard solution of N-acetyl L-cysteine was prepared by dissolving $12.5 \mathrm{mg}$ in $50 \mathrm{ml}$ milli Q water. The reference standard solution was used to prepare the calibration and the quality control samples.
For the assessment of accuracy and precision, the quality control samples were

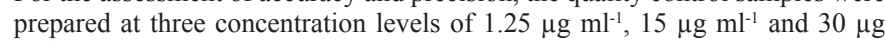
$\mathrm{ml}^{-1}$. The pharmaceutical dosage form Mucinac-600 was obtained from the local market. A $0.038 \mathrm{M} \mathrm{KI}$ and $0.007 \mathrm{M} \mathrm{KIO}_{3}$ (BDH Chemicals limited Poole, England) solutions were freshly prepared.

Proposed procedure for the determination of $\mathrm{N}$-acetyl L-cysteine

$\mathrm{N}$-acetyl L-cysteine standard solution equivalent to $1.25 \mu \mathrm{g} \mathrm{m} \mathrm{m}^{-1}-30 \mu \mathrm{g}$ $\mathrm{ml}^{-1}$ were pipetted into a series of $10 \mathrm{ml}$ standard flask. To each standard flask $1.5 \mathrm{ml}$ of $0.0072 \mathrm{M} \mathrm{KIO}_{3}$ was added followed by addition of $1.8 \mathrm{ml}$ of 0.026 M KI and made up to the mark with milli Q water. The content of the each standard flasks were thoroughly mixed and was subjected to spectrophotometric studies and increase in the absorbance was recorded at $352 \mathrm{~nm}$. The absorbance-time plot was prepared and initial rate of the reaction ( $v$ ) at various concentrations was obtained by measuring the slope of the tangent of the previously plotted absorbance-time curve. The analyses were performed at $30 \pm 1{ }^{\circ} \mathrm{C}$.

Determination of $\mathrm{N}$-acetyl $\mathrm{L}$-cysteine in commercial dosage form

Two tablets equivalent to $1200 \mathrm{mg}$ of $\mathrm{N}$-acetyl L-cysteine was weighed crushed and the amount of the crushed tablet equivalent to $250 \mathrm{mg}$ of N-acetyl L-cysteine was dissolved in $1000 \mathrm{ml}$ of milli Q water in a volumetric flask. The content of the flask was sonicated for 5 minutes and filtered. N-acetyl Lcysteine equivalent to $1.25-30 \mu \mathrm{g} \mathrm{ml}^{-1}$ were pipetted and analyzed by the above mentioned procedure. The amount of the drug was calculated either from the calibration graph or from the linear regression equation.

Optimization of variables

During the experiments the optimum condition responsible for the formation of the yellow colored products was studied and the same was maintained throughout the determination process.

Effect of the concentration of $\mathrm{KIO}_{3}$

The effect of potassium iodate on the initial rate of reaction was studied in the concentration range of $1.43 \times 10^{-4} \mathrm{M}-1.22 \times 10^{-3} \mathrm{M}$ (Figure 1) keeping the rest variables constant where $\mathrm{NAC}=1.84 \times 10^{-4} \mathrm{M}$ and $\mathrm{KI}=7.64 \times 10^{-3} \mathrm{M}$. It was observed that the initial rate of reaction increased with the increase in concentration of $\mathrm{KIO}_{3}$ and became constant at $9.29 \times 10^{-4} \mathrm{M}$ and remained as such upto $1.22 \times 10^{-3} \mathrm{M}$. Therefore, $1.07 \times 10^{-3} \mathrm{M}$ was selected as optimum.

Effect of the concentration of KI

The effect of KI on the initial rate was also studied to select the optimum concentration. For this purpose, the reagent was studied in the range of $1.69 \times$ $10^{-3} \mathrm{M}-1.125 \times 10^{-2} \mathrm{M}$ keeping the constant concentration of drug $\left(1.84 \times 10^{-4}\right.$ M) and $\mathrm{KIO}_{3}\left(1.07 \times 10^{-3} \mathrm{M}\right)($ Figure 2). Here also the initial rate increased with increase in time and became constant at $8.44 \times 10^{-3} \mathrm{M}$ and remained as such upto $1.13 \times 10^{-2} \mathrm{M}$. Therefore, $1.013 \times 10^{-2} \mathrm{M}$ was selected as optimum for the color development process.

\section{MS Operating condition}

The selection and optimization of the MS condition is yet another challenge face by the analyst to get the highest sensitivity for the drug compound. 
The optimized MS conditions are Capillary Voltage, $3.0(\mathrm{KV})$; cone voltage, $50 \mathrm{~V}$; source temperature, $120^{\circ} \mathrm{C}$; desolvation temperature, $300^{\circ} \mathrm{C}$; desolvation gas flow, 600 1/h; cone gas flow, $601 / \mathrm{h}$.

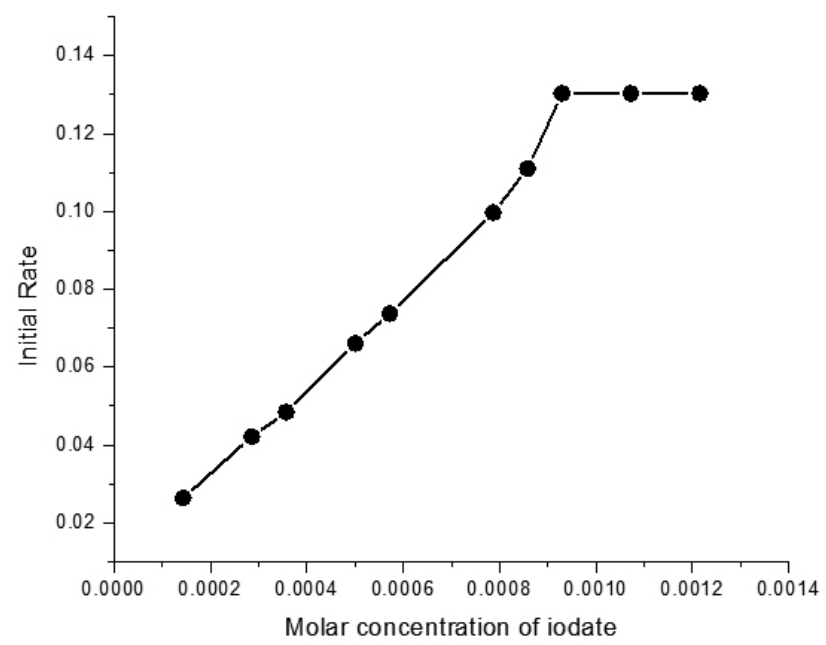

Figure 1: Effect of Molar concentration of Potassium iodate on the initial rate of reaction

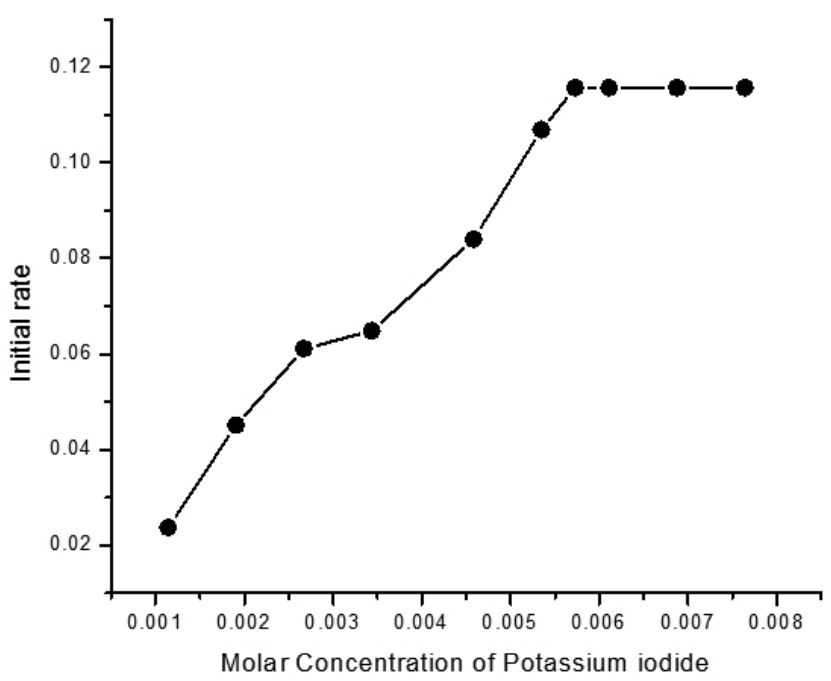

Figure 2: Effect of Molar concentration of Potassium iodide on the initial rate of reaction

\section{RESULTS AND DISCUSSION}

\section{Spectral Studies}

Spectral studies were performed comparing the obtained spectra of pure $\mathrm{N}$-acetyl L-cysteine, the blank containing mixture of potassium iodate and potassium iodide and the reaction complex of the drug and the reagent. The aqueous solution of NAC absorbs maximally at $236 \mathrm{~nm}$ while the mixture of potassium iodide and potassium iodate shows an absorption maximum band at $289 \mathrm{~nm}$. The course of the reaction starts when the drug is added to the reagent a new characteristics band appears at $352 \mathrm{~nm}$. This band is due to the oxidation of the drug by the mixture of iodate and formation of triiodide ion. The schematic representation of the spectral studies is mentioned in Figure 3.

Mechanism of color reaction

The addition of the drugs to the mixture of iodide and iodate resulted in the formation of a yellow colored product. This yellow colored compound is attributed to the oxidation of thiol moiety of the N-acetyl L cysteine with the mixture of iodate and iodide. In the literature, mixture of iodate and iodide has been reported to be used as oxidizing agent ${ }^{13,14}$. It has been reported that the aliphatic thiols undergo oxidation and results in the formation of three types of compounds which may be disulfides (RSSR) or sulfinic acid $\left(\mathrm{RSO}_{3} \mathrm{H}\right)$ or it may be sulphonic acid ${ }^{3}$. In a specific case, Hird and Yates reported that oxidation of cysteine by iodate result in the formation of disulfide cysteine ${ }^{15}$. In the similar way the in the current investigation $\mathrm{N}$-acetyl L cysteine undergoes oxidation by iodate resulting in the formation of disulfide N-Acetyl cysteine. Further, the generation of triiodide ion takes place upon the oxidation of iodide by iodate in presence of the acid moiety of the drug. The formation of disulfide $\mathrm{N}$ - acetyl cysteine was confirmed after the reaction product was subjected to mass spectrometry to obtain the ion spectra. It was observed that the $\mathrm{m} / \mathrm{z}$ ratio of the oxidation product was found at 326, clearly indicating that dimerization has taken place resulting in the formation of disulfide acetyl cysteine. The formation of the dimer takes place slowly which can be evident by the change in absorbance with respect to time. The same was taken into account and kinetic method was adopted for quantification of the drug. The mechanism of the reaction is mentioned in Scheme 1.The ion spectra of the oxidation product are mentioned in Figure 4.

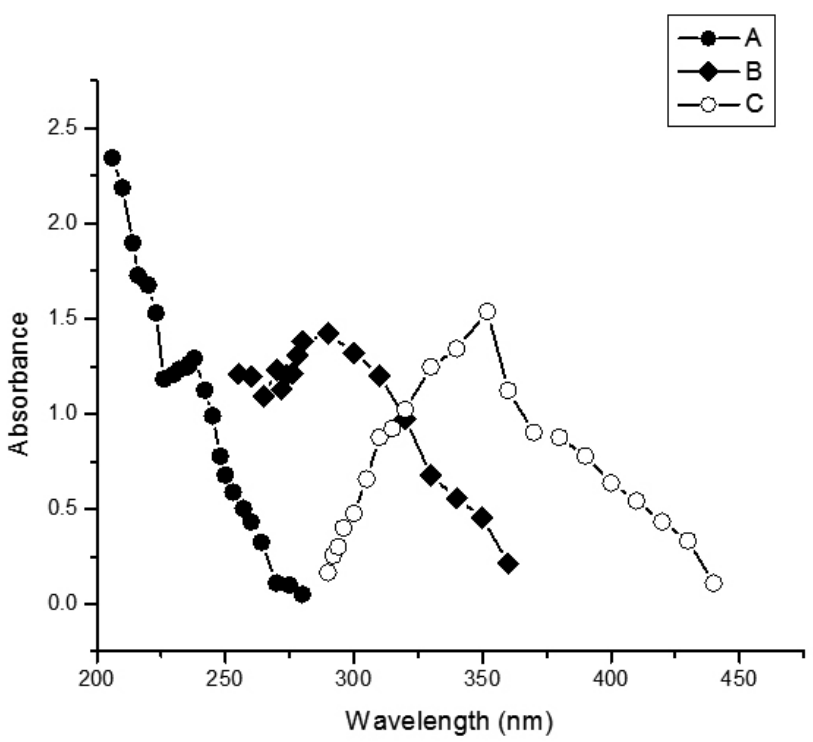

Figure 3: Absorption spectra of A) $1.76 \times 10^{-4} \mathrm{M} \mathrm{N}$-acetyl L-cysteine in Milli Q water B) Blank solution containing $1.07 \times 10^{-3} \mathrm{M} \mathrm{KIO}_{3}$ and $1.01 \times 10^{-2}$ $\mathrm{M} \mathrm{KI}$ in Milli Q water C) $1.531 .01 \times 10^{-4} \mathrm{M} \mathrm{N}$ acetyl L cysteine $\left(25 \mu \mathrm{g} \mathrm{ml}^{-1}\right)$, $1.07 \times 10^{-3} \mathrm{M} \mathrm{KIO}_{3}$ and $1.01 \times 10^{-2} \mathrm{M} \mathrm{KI}$ in Milli Q water.

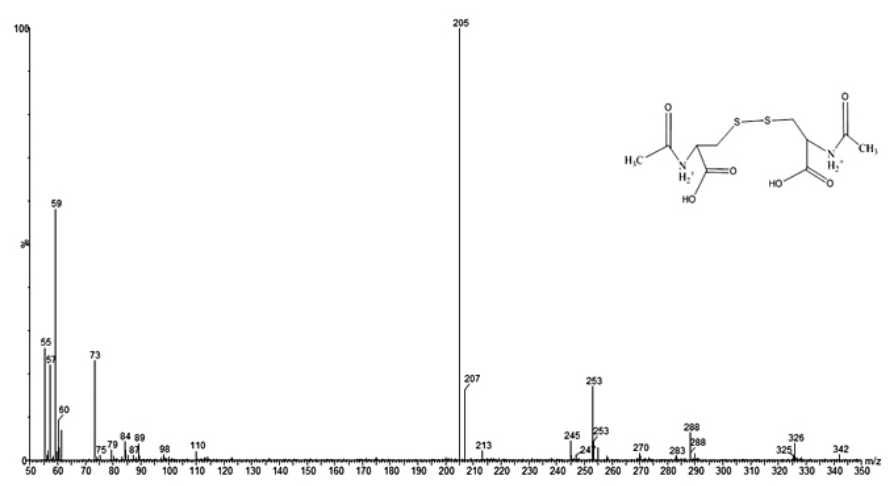

Figure 4: Full ion spectra of the oxidation product of N-acetyl L-cysteine.

Analytical data and method validation

Kinetic parameters of the initial rate method were investigated under pseudo first order condition which was established with respect to the reagent concentration.Absorbance-time plot was used to determine the initial rate of reaction by measuring the slopes of the initial tangent to the previously mentioned plot. Based on the experimental observations, the kinetic equation for the reaction can be written as 
$\operatorname{Rate}(v)=\mathrm{k}[\mathrm{C}]^{\mathrm{n}}\left[\mathrm{KIO}_{3}\right]^{\mathrm{m}}[\mathrm{KI}]^{\mathrm{l}}$

For $\left[\mathrm{KIO}_{3}\right] \geq 1.07 \times 10^{-3} \mathrm{M}$ and $[\mathrm{KI}] \geq 1.01 \times 10^{-2} \mathrm{M}$ at $303 \mathrm{~K}$.

The above equation reduces to:

Rate $(v)=\mathrm{k}_{\gamma}[\mathrm{C}]^{\mathrm{n}}$

In the above equation $\mathrm{k}_{\mathrm{y}}$ is the pseudo-order rate constant, $\mathrm{C}$ is the concentration of $\mathrm{N}$-acetyl $\mathrm{L}$ cysteine and $\mathrm{n}$, the order of reaction.

In the logarithmic form, the equation can be written as:

$\log ($ rate $)=\log \mathrm{k}_{\gamma}+\mathrm{n} \log \mathrm{C}$

Absorbance-time plot for the first ten minutes of the reaction (Figure 5) was prepared and initial rates of the reaction at each concentration was determined and summarized in Table 1. Linear regression equation was derived from the plot of $\log$ rate versus $\log \mathrm{C}$ which came out to be

$\log ($ rate $)=-2.197+1.061 \log C$

Coefficient of correlation, $r$ was found to be 0.9984 . The value of $n$ in the equation confirmed that the reaction is first order with respect to $\mathrm{N}$ - acetyl cysteine.

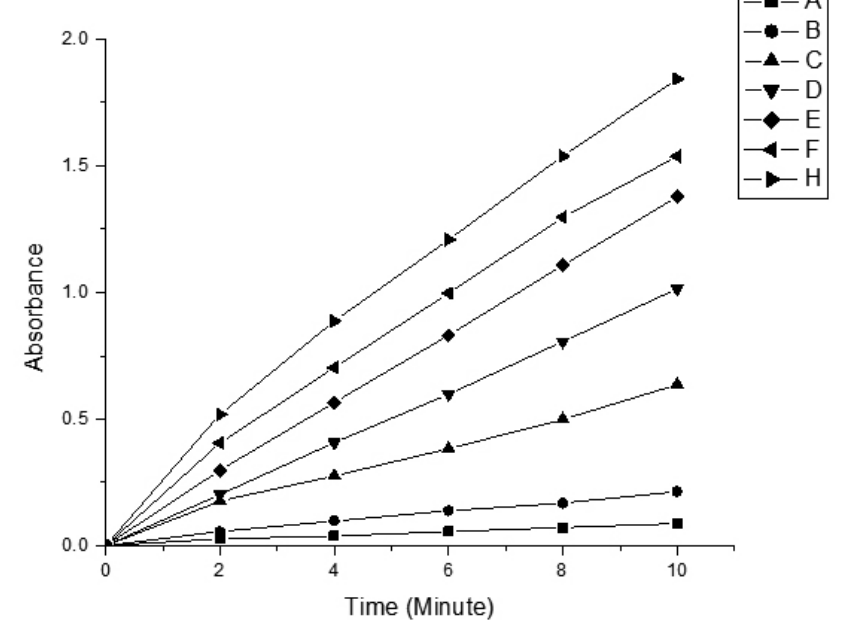

Figure 5: Absorbance-time curve for initial rate of reaction at different concentration of N-acetyl L-cysteine A) $7.66 \times 10^{-6}$, B) $1.53 \times 10^{-5}$, C) $4.60 \times$ $10^{-5}$, D) $9.19 \times 10^{-5}$, E) $1.38 \times 10^{-4}$, F) $1.53 \times 10^{-4}$, G) $1.84 \times 10^{-4}$

Table 1. Initial rate of reaction at different concentration of N-Acetyl Lcysteine keeping $\left[\mathrm{KIO}_{3}\right]$ and $[\mathrm{KI}]$ constant.

\begin{tabular}{|c|c|c|c|}
\hline $\mathrm{C},[$ Drug $] \mathrm{mol}^{-1}$ & $\log C$ & $\begin{array}{c}\text { Initial rate of } \\
\text { reaction }(U) \text { mol } \\
L^{-1} \mathrm{~S}^{-1}\end{array}$ & $\log U$ \\
\hline $7.66 \times 10^{-6}$ & -5.1157 & $7.750 \times 10^{-3}$ & -2.1107 \\
\hline $1.53 \times 10^{-5}$ & -4.8153 & $1.798 \times 10^{-2}$ & -1.7452 \\
\hline $4.60 \times 10^{-5}$ & -4.3372 & $4.803 \times 10^{-2}$ & -1.3185 \\
\hline $9.19 \times 10^{-5}$ & -4.0367 & $9.016 \times 10^{-2}$ & -1.0450 \\
\hline $1.38 \times 10^{-4}$ & -3.8601 & $1.317 \times 10^{-1}$ & -0.8805 \\
\hline $1.53 \times 10^{-4}$ & -3.8153 & $1.409 \times 10^{-1}$ & -0.8512 \\
\hline $1.84 \times 10^{-4}$ & -3.7352 & $1.576 \times 10^{-1}$ & -0.8025 \\
\hline
\end{tabular}

Further, by plotting the initial rate of reaction versus initial concentration of NAC a calibration curve was prepared which showed a linear response over the concentration range of $1.25 \mu \mathrm{g} \mathrm{ml}^{-1}-30.0 \mu \mathrm{g} \mathrm{ml}^{-1}$. The statistical treatment of the calibration data $(\mathrm{n}=7)$ was made to calculate slope, intercept and correlation coefficient. The statistical treatment of the rate versus concentration of $\mathrm{NAC}\left(\mu \mathrm{gml}^{-1}\right)$ produced the following linear regression equation:

Rate $=-6.01 \times 10^{-6}+1.14 \times 10^{-3} \mathrm{C}$ where, correlation coefficient (r) was found to be 0.9966 . The analytical data is summarized in Table 2. From the table it is evident that the values of the confidence limit are noticeably low which indicates high reproducibility of the developed initial rate method.

Table 2: Optical characteristics and analytical data of initial rate.

\begin{tabular}{|c|c|}
\hline Parameters & Values \\
\hline Measured wavelength $(\mathrm{nm})$ & 352 \\
Beer's law range $\left(\mu \mathrm{g} \mathrm{m}^{-1}\right)$ & $1.25-30$ \\
\hline Regression equation & $-6.0 \times 10^{-6}+1.14 \times 10^{-3}$ \\
\hline Standard deviation & $6.36 \times 10^{-6}$ \\
\hline Standard deviation of slope $\left(\mathrm{S}_{\mathrm{a}}\right)$ & $4.33 \times 10^{-6}$ \\
\hline Standard deviation of intercept $\left(\mathrm{S}_{\mathrm{b}}\right)$ & $4.25 \times 10^{-5}$ \\
\hline Correlation coefficient $(\mathrm{r})$ & 0.9966 \\
\hline Detection limit $\left(\mu \mathrm{g} \mathrm{ml}^{-1}\right)$ & $1.84 \times 10^{-2}$ \\
\hline Quantitation limit $\left(\mu \mathrm{g} \mathrm{ml}^{-1}\right)$ & $5.58 \times 10^{-2}$ \\
\hline Variance & $4.04 \times 10^{-11}$ \\
Molar absorptivity $\left(1 \mathrm{~mol}^{-1} \mathrm{~cm}^{-1}\right)$ & $1.19 \times 10^{4}$ \\
\hline
\end{tabular}

\section{Method validation}

To be considered reliable for the analysis, all the developed analytical procedure must be validated as per the guidelines of the regulatory authorities. This validation is not only significant for regulatory commitments, but also for their long-term application. The parameters for the method validation considered in this study areconfirmation of identity, solution stability, selectivity/ specificity, linearity, accuracy and precision, limits of detectionand quantitation, recovery and robustness.

\section{Specificity}

Specificity of the current method was checked by analyzing the synthetic mixture of NAC and common excipient used in the tablet formulations. The synthetic mixture was prepared by taking various excipients such as sodium stearyl fumarate, magnesium stearate, starch, lactose and talc. During the study it was observed that these common excipients do not interfere in the determination process.

Preparation of forced degradation products and its characterization

Degradation product of N-acetyl L-cysteine was prepared and characterized using mass spectrometry. The degradation product was prepared by heating $1.53 \times 10^{-4} \mathrm{M} \mathrm{NAC}$ in presence of $1.25 \times 10^{-2} \mathrm{M} \mathrm{NaOH}$. The content of the mixture was heated at $100{ }^{\circ} \mathrm{C}$ for 30 minutes. The content of the sample was cooled and was subjected to mass spectrometric analysis and spectra were obtained (Figure 6). The study of the spectra shows that due to stress condition acetamide group breaks away from the parent compound leaving behind a compound with $\mathrm{m} / \mathrm{z}$ ratio of 103 . Since acetamide is not stable under the basic condition it readily converts into acetic acid having $\mathrm{m} / \mathrm{z}$ ratio of 59 . In the similar fashion in addition to the basic stress condition, NAC was exposed to other stress conditions such as acid, thermal and oxidative degradation. In acid degradation $1.53 \times 10^{-4} \mathrm{M}$ NAC was heated along with $5.010^{-4} \mathrm{~N} \mathrm{HCl}$ for 30 minutes at $100^{\circ} \mathrm{C}$. The content of the sample was made to cool at room temperature and was analyzed used mass spectrometer, the spectra obtained (Figure 7) shows that under acid degradation major products formed is having mass number 121. From the MS spectra formation of cysteine can be predicted. Cysteine was formed by the removal of acetyl group by breaking the N-C bond of NAC. In the thermal degradation $100 \mathrm{mg}$ of NAC was transferred to $10 \mathrm{ml}$ beaker and was kept as such in oven at $100{ }^{\circ} \mathrm{C}$ for 30 minutes. The heated sample was cooled and $1.53 \times 10^{-4} \mathrm{M}$ NAC solution was prepared and was subjected to mass spectrometric analysis. The compound obtained having mass 119.04; this may be attributed to the removal of $\mathrm{CO}_{2}$ form the parent compound (Figure 8). In the similar fashion when $1.53 \times 10^{-4} \mathrm{M}$ NAC was subjected to peroxide degradation condition by heating the parent compound in presence of $5 \mathrm{ml}$ of $3 \% \mathrm{H}_{2} \mathrm{O}_{2}$ for $30 \mathrm{~min}$ at $100{ }^{\circ} \mathrm{C}$. The mass spectra of the peroxide degradation was obtained (Figure 9) which shows major compound is formed at $m / z 160$ this compound may be formed due to the oxidation of sulfur and removal of acetyl group by breaking the $\mathrm{N}-\mathrm{C}$ bond of intermediate compound 2-acetamido-3-sulfopropanoic acid.

Linearity

Linearity of developed method was assessed at seven concentration level of $1.25,2.50,7.50,15.0,22.5,25.0$ and $30.0 \mu \mathrm{g} \mathrm{ml}^{-1}$. Five replicate analyses 
were performed at each concentration level.

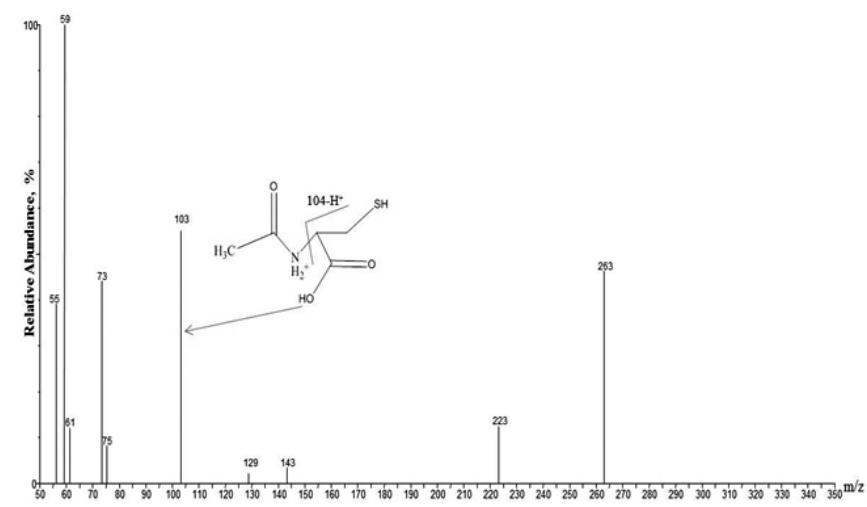

Figure 6: Full ion spectra of the basic degradation product of N-acetyl L-cysteine.

\section{Accuracy and precision}

To check the accuracy and the precision of the developed method intraday assay and interday analyses were performed. For this $\mathrm{N}$-acetyl L-cysteine content was analyzed at three concentration level for one day (intraday) and for three consecutive days (interday). The analyses were performed at 1.25, 15.0 and $30.0 \mu \mathrm{g} \mathrm{ml}^{-1}$. For the accuracy and precision experiments five replicate analyses were performed at each concentration level.The results of the precision experiments are summarized in Table 3.

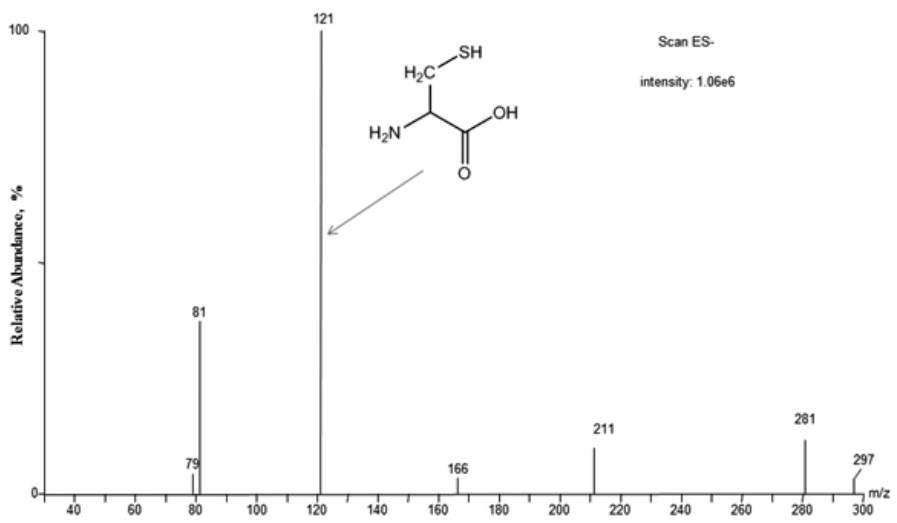

Figure 7: Full ion spectra of the acid degradation product of N-acetyl Lcysteine.

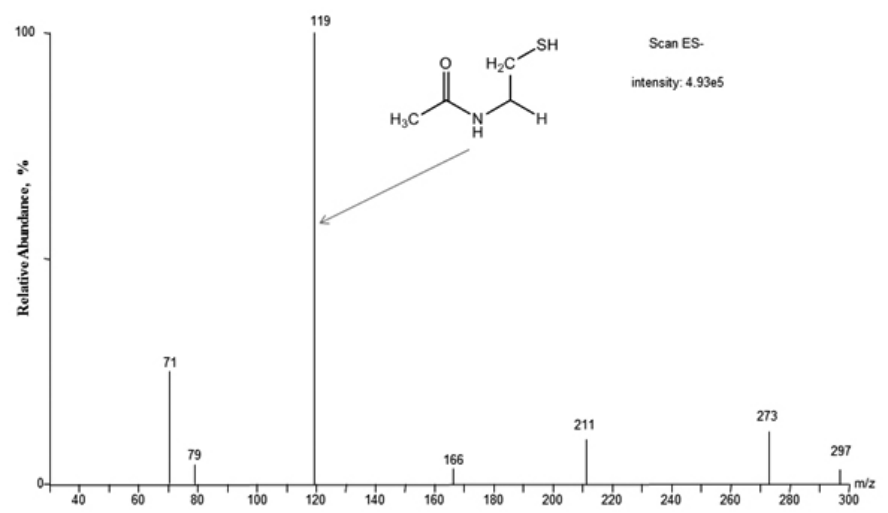

Figure 8: Full ion spectra of the thermal degradation product of N-acetyl L-cysteine.

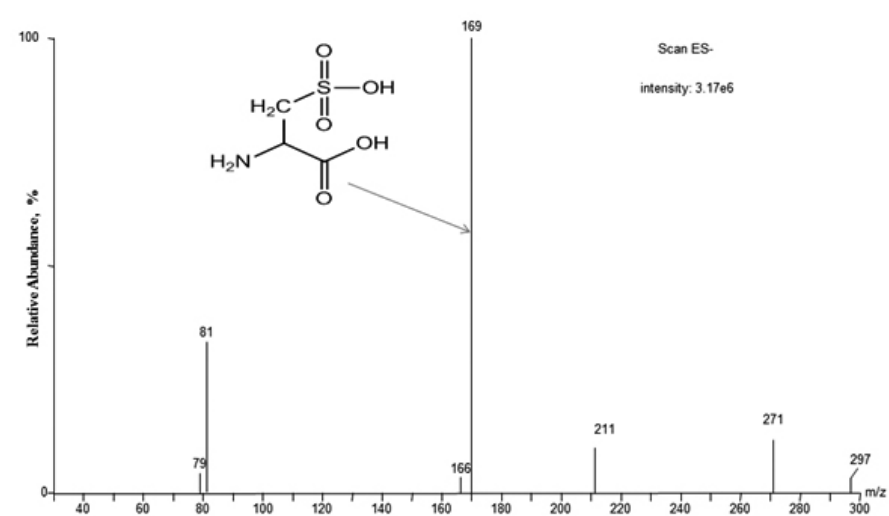

Figure 9. Full ion spectra of the peroxide degradation product of $\mathrm{N}$-acetyl L-cysteine.

Table 3. Evaluation of accuracy and precision of the proposed method by intraday and interday assay.

\begin{tabular}{|c|c|c|c|c|c|}
\hline \multirow{2}{*}{$\begin{array}{l}\text { Proposed } \\
\text { Methods }\end{array}$} & \multicolumn{2}{|c|}{ Amount $\mu \mathrm{g} \mathrm{ml}^{-1}$} & \multirow{2}{*}{$\begin{array}{l}\mathrm{RSD}^{\mathrm{a}} \\
(\%)\end{array}$} & \multirow{2}{*}{$\mathrm{SAE}^{\mathrm{b})}$} & \multirow{2}{*}{ C. $L^{\mathrm{c})}$} \\
\hline & Taken & Found $\pm \mathrm{SD}^{\mathrm{a})}$ & & & \\
\hline \multirow[t]{3}{*}{$\begin{array}{c}\text { Intra Day } \\
\text { Assay }\end{array}$} & 1.25 & $1.24 \pm 0.014$ & 1.14 & 0.006 & 0.017 \\
\hline & 15.0 & $15.02 \pm 0.210$ & 1.40 & 0.094 & 0.261 \\
\hline & 30.0 & $30.03 \pm 0.312$ & 1.04 & 0.140 & 0.388 \\
\hline \multirow[t]{3}{*}{$\begin{array}{c}\text { Interday } \\
\text { Assay }\end{array}$} & 1.25 & $1.26 \pm 0.023$ & 1.87 & 0.011 & 0.029 \\
\hline & 15.0 & $14.97 \pm 0.219$ & 1.46 & 0.098 & 0.272 \\
\hline & 30.0 & $30.08 \pm 0.360$ & 1.20 & 0.161 & 0.447 \\
\hline
\end{tabular}

${ }^{a}$ mean of five independent analyses.

SAE, Standard analytical error

C.L. Confidence limit at $95 \%$ confidence level and four degrees of free$\operatorname{dom}(\mathrm{t}=2.776)$

Further, standard addition technique was applied to check the validity of the proposed method through the recovery studies. In this experiment, known amount of drug was added to the market formulations at three concentration points by doing five replicate analysis by the recommended procedures to quantitatively measure the drug. The results of standard addition experiments are listed in Table 4. The results from the table indicate that the initial rate method have excellent recoveries (99.79-100.17) with low RSD value (1.00$1.51)$. The recovery results also prove that the method is free from the effect and interference from the common excipients.

Limits of detection (LOD) and quantitation (LOQ)

Limit of detection can be defined as minimum amount of analyte that can be reliably detected but not necessarily quantitated in an analytical procedure. The limit of quantitation is the minimum amount of analyte that can be quantitated with full accuracy. An important part of method validation, limit of detection (LOD) and limit of quantitation (LOQ) were calculated using the following equation ${ }^{16}$.

$$
\mathrm{LOD}=3.3 \times \mathrm{S}_{\mathrm{d}} / \mathrm{b} \quad \mathrm{LOQ}=10 \times \mathrm{S}_{\mathrm{d}} / \mathrm{b}
$$

Where, $S_{d}$ is the standard deviation and $b$ is the slope of the calibration line. In our current investigation standard deviation value of the standard plot (initial rate $v s$ initial concentration) comes out to be $6.36 \times 10^{-6}$ while the slope of the calibration line was 0.00114 . Putting the two values in the above mentioned equation the limit of detection (LOD) and limit of quantitation (LOQ) of the developed method was found to be $0.018 \mu \mathrm{g} \mathrm{ml}^{-1}$ and $0.056 \mu \mathrm{g} \mathrm{ml}^{-1}$, respectively. The variance was also calculated as the square of the standard deviation was found to be $4.04 \times 10^{-11}$. Such a low value of variance shows negligible scattering of the experimental data points round the line of regression. 
Table 4. Standard addition method for the determination of N-Acetyl L-cysteine in commercial dosage form.

\begin{tabular}{|c|c|c|c|c|c|c|}
\hline \multirow[t]{2}{*}{ Formulations } & \multicolumn{3}{|c|}{$\begin{array}{l}\text { Initial rate method } \\
\text { Amount }\left(\mu \mathrm{g} \mathrm{m}^{-1}\right)\end{array}$} & \multirow[b]{2}{*}{$\begin{array}{c}\text { Recovery } \\
(\%)\end{array}$} & \multirow[b]{2}{*}{$\begin{array}{l}\text { RSD } \\
(\%)\end{array}$} & \multirow[b]{2}{*}{ SAE } \\
\hline & Taken & Added & Found \pm SD & & & \\
\hline \multirow{3}{*}{ Mucomelt } & 2.5 & 1.25 & $3.75 \pm 0.057$ & 100.17 & 1.51 & 0.025 \\
\hline & 2.5 & 10.0 & $12.47 \pm 0.167$ & 99.79 & 1.34 & 0.075 \\
\hline & 2.5 & 27.5 & $30.01 \pm 0.300$ & 100.03 & 1.00 & 0.134 \\
\hline
\end{tabular}

\section{Robustness}

Robustness of the proposed initial rate method relative to the operational parameters was closely examined. The robustness of the proposed method was checked by estimating the content of the drug in the marketed formulation by slightly changing the experimental conditions deliberately. The changed parameter includes

Volume of $0.0072 \mathrm{M} \mathrm{KIO}_{3}= \pm 0.2 \mathrm{ml}$

Volume of $0.026 \mathrm{M} \mathrm{KI}= \pm 0.2 \mathrm{ml}$

Under the changed experimental condition a quality control sample $25 \mu \mathrm{g}$ $\mathrm{ml}^{-1}$ was analyzed using the proposed method. The results of the five replicate analyses show that the percent recovery and RSD was found to be 99.92 and 1.26 , respectively.

\section{Applicability of the proposed method}

The proposed method was used to estimate NAC in pharmaceutical dosage forms. Equivalence testing was performed and the results of the proposed method were compared to that of the reference method using the point and interval hypothesis ${ }^{17}$. The results are summarized in Table $\mathbf{5}$ indicate that $\mathrm{t}-$ value and the $\mathrm{F}$ value at $95 \%$ confidence level are well within the limits of their theoretical values ${ }^{18}$. The results indicate that there is no significant difference between the proposed and the reference method ${ }^{19}$ which is a comparative method which has been publish earlier. It is also evident from the table 5 that true bias of NAC sample is smaller than $\pm 2 \%$ this proves the reliability of the proposed method with acceptable recovery based on the guidelines of the Canadian health protection branch ${ }^{20}$ which permits a bias of $\pm 2 \%$ where, the tolerable limit lies within $\theta_{\mathrm{L}}=0.98$ and $\theta_{\mathrm{U}}=1.02$. Comparing the proposed and the reference method we find that the proposed method is less time consuming and the analysis time is half the time of the proposed method. The reference method uses ferric sulfate, ferrozine and sodium perchlorate in addition to the drug where the concentrations of each reagent involved are taken into account in addition to the proper optimization of ionic strength which makes the method tedious. The molar absorptivity of the proposed method is $1.19 \times$ $10^{4} \mathrm{~mol}^{-1} \mathrm{~cm}^{-1}$ similar to that of the reference method which is $2.26 \times 10^{4} 1 \mathrm{~mol}^{-}$ ${ }^{1} \mathrm{~cm}^{-1}$. In the precision studies the reference article reported a precision of 1.53 $\%$ while in the proposed method authors performed the precision six time, at all the points the RSD was lower than the reference method except at one point. The validation of the analytical methods involving pharmaceuticals follow the international conference on harmonization guidelines which also recommends the calculation of limit of detection (LOD) and limit of quantitation (LOQ) as a part of validation parameter. The reference article lacks this important information while from the proposed method it is clear that the limit of quantitation is well below the linear range.

Table 5: Point and interval hypothesis tests: Comparison of the proposed method with the reference method [8].

\begin{tabular}{|c|c|c|c|c|c|c|c|c|}
\hline \multirow[b]{2}{*}{ Formulation } & \multicolumn{2}{|c|}{ Point Hypothesis } & \multicolumn{4}{|c|}{ Interval hypothesis } & \multicolumn{2}{|c|}{ Reference method } \\
\hline & Recovery & $\mathrm{RSD}^{\text {a) }}$ & t- value & F- value & $\theta_{\mathrm{L}}$ & $\theta_{\mathrm{U}}$ & Recovery & $\mathrm{RSD}^{\text {a) }}$ \\
\hline $\begin{array}{c}\text { Mucomelt } \\
\text { Batch } 1\end{array}$ & 100.01 & 1.47 & 1.27 & 0.002 & 0.9998 & 1.0007 & 99.98 & 1.77 \\
\hline $\begin{array}{c}\text { Mucomelt } \\
\text { Batch } 2\end{array}$ & 100.14 & 1.40 & 1.04 & 0.003 & 0.9998 & 1.0006 & 100.12 & 1.80 \\
\hline
\end{tabular}

\section{CONCLUSION}

The proposed method exploits the oxidizing property of the potassium iodate to oxidize $\mathrm{N}$-acetyl cysteine for the routine quality control analysis of the drug. The method is very simple having no pre-treatment process prior to analysis. The oxidation and the degradation products were characterized by mass spectrometry and their structures are ascertained based on their $\mathrm{m} / \mathrm{z}$ value. The main objective of the forced degradation studies is to demonstrate the specificity of the developed method. This forced degradation studies also helps to identify the possible pathways of the degradation and the products formed during the storage and the transportation of the drug materials. The determining technique is simple and of low cost. Thus the methods can be used frequently in the quality control laboratories, academic institutions and pharmaceutical industries.

\section{ACKNOWLEDGEMENTS}

The authors extend their appreciation to the Deanship of Scientific Research, College of Science Research Center, King Saud University, Riyadh, Saudi Arabia for supporting this project.

\section{REFERENCE}

1. D.A. Algren, http://www.who.int/selection medicines/committees/subcommittee/2/acetylcysteine_rev.pdf.

2. http://uuhsc.utah.edu/poison/healthpros/utox/Vol7_No1.pdf.

3. O. Dean, F. Giorlando, M. Berk, Archives Toxicol. 60, 401, (1987).

4. W. Barnner Jr, M. Koch, D.M. Capin, Toxicol. \& Appl. Pharmacol. 83,
142, (1986)

5. M. Al-Ghannam, A.M. El-Brashy, B.S. Al-Farhan, IL Farmaco 57, 625, (2002).

6. M.P. Bartolomeo, F. Maisano, J. Biomol. Techn. 17, 131, (2006).

7. W. Wu, G. Goldstein, C. Adams, R.H. Matthews, N. Ercal, Biomed. Chromatogr. 20, 415, (2006).

8. A. Martinovic, N. Radic. Anal. Lett. 40, 2851, (2007).

9. M.C.G. Alvarez-Coque, M.J.M. Hernandez, R.M.V. Camana, C.M. Fernandez, Analyst 114, 975, (1989).

10. L. Kukoc-Modun, N. Radić, Anal. Sci. 26, 491, (2010).

11. N. Rahman, M.R.Siddiqui, S.N.H. Azmi, Chem. Pharm. Bull. 54, 626, (2006).

12. N. Radić, L. Kukoc-Modun, M. Biocic, Croat. Chem. Acta 86, 65 (2013).

13. N. Rahman, Y. Ahmad, S.N.H. Azmi, AAPS PharmSciTech 6, E543, (2005).

14. P. Sami, N. Mariselvi, K. Venkateshwari, A. Sarathi, K. Rajasekaran, J. Chem. Sci. 122, 335, (2010).

15. F.J.R. Hird, J.R. Yates, Biochem. J. 80, 612, (1961).

16. J. Ermer, J. Pharm. Biomed. Anal. 24, 755, (2001).

17. C. Hartmann, J. Smeyers-Verbeke, W. Penninckx, Y.V. Heyden, P. Vankeerberghen, D. L. Massart, Anal. Chem. 67, 4491, (1995).

18. G.D. Christian, Analytical Chemistry, John Wiley and Sons, Inc., Singapore, 2004

19. M.A. Eid, Mikrochim. Acta 129, 91, (1998).

20. Canada Health Protection Branch, Drugs Directorate Guidelines, Acceptable Methods, Ministry of National Health and Welfare, Draft, 1992 